affected development of psychosocial maladjustment and stigma.

We are grateful to the British Epilepsy Association Research Fund for sponsoring this research and to the National Society for Epilepsy for their assistance in making the research possible. The medical aspects of the national general practice study of epilepsy have been generously supported by Action Research and the Brain Research Trust. We also acknowledge Dr J W Sander and Dr Y M Hart for their assistance.

\footnotetext{
I Levine R, Banks S, Berg B. Psychosocial dimensions of epilepsy: a review of the literature. Epilepsia 1988;29:805-16.

DodrillCB, Breyer DN, Diamond MB, Dubinsky BL, Greary BB. Psychosocial problems among adults with epilepsy. Epilepsia 1989;25:168-75.
}

3 Shorvon SD. The temporal aspects of prognosis in epilepsy. $f$ Neurol Neurosurg Psyckiatry 1984;47:1157-65.

4 Hart YM, Sander JW, Johnson AL, Shorvon SD. National general practice study of epilepsy: recurrence after a first seizure. Lancet 1990;336:1271-4.

5 Sander JW, Hart YM, Johnson AL. Shorvon SD. National general practice study of epilepsy: newly diagnosed epileptic seizures in a general population. Lancet 1990;336:1267-71.

6 Hart YM, Sander JW, Shorvon SD. National general practice study of epilepsy and epileptic seizures: objectives and study methodology of the largest reported prospective cohort study of epilepsy. Neuroepidemiology 1989;8: 221-7.

7 Chaplin JE, Yepez R, Shorvon SD, Floyd M. A quantitative approach to measuring the social effects of epilepsy. Neuroepidemiology 1990;9:151-8. Nunnally JC Psychometric theory. New Delhi: Tat McGaw-Hill, 1981.

9 Wright GN. Rehabilitation and the problem of epilepsy. In: Chigier $E$, right GN. Rehabilitation and the problem of epilepsy. In: Chigier E, New dimensions in rehabilitation. Tel Aviv: Gomeh Scientific, 1978:492-6. 1972;13:121-31.

(Accepted 12 March 1992)

Managing Change in Primary Care

\title{
Learning from the past
}

\author{
Justin Allen, Andrew Wilson
}

This is the second in a series of articles looking at how to manage change in general practice

\section{Countesthorpe, \\ Leicestershire \\ Justin Allen, general \\ practitioner}

Department of General Practice, University of Leicester, Leicester LE2 7LX

Andrew Wilson, senior lecturer

Correspondence to: $\mathrm{Dr}$ Wilson.

Series edited by: Dr M Pringle.

BMF 1992;304: 1418-20
Doctors in a three partner practice do all their own on call out of hours work in an equal rota of nights and weekends. The senior partner is aged 56 . He has given vague hints that he is planning to retire at 60 but has never confirmed this. His two junior partners have been in the practice for three and four years respectively. At a partners' meeting he announces that he is proposing to give up his night work as he is finding this increasingly irksome, and has done it uninterrupted for the previous 27 years. He is proposing that the change should take effect from the beginning of the next quarter, in six weeks' time. His proposal is that the junior partners would take over his responsibility and in return would share all the income received for night visists. Much to his surprise he is met with an angry refusal. Hurt and rejected by this response, he gets angry and threatens to dissolve the partnership and the meeting breaks up in uproar.

Most practices will be able to recall similar examples of proposed change going wrong. But most can also point to changes that have been successfully implemented and found to be beneficial. Change, or the possibility of it, is with us all the time. This ranges from the major externally imposed upheavals that have been a feature of general practice over the past few years to minor adjustments within the practice. All practices, therefore, have a wealth of experience of change. Can they use these experiences to improve their management of change? According to Socrates, experience has taught our best flautists, but it has also taught our worst. The following questions allow a practice to review its changes over recent years.

\section{How much have we changed?}

Has the practice been either too stagnant or too unstable? The degree of change and its frequency should be considered. One major change, such as the breaking up of a partnership, might have prolonged repercussions. However, frequent small changes may also have an impact. In industrial settings frequent environmental changes have been shown to boost productivity (the Hawthorne effect). In contrast, general practitioners often complain about the frequency of minor changes, such as to standard referral forms or protocols for child health surveillance.

Have changes been in response to external events or have they been initiated internally? Changes resulting from a perceived need are clearly more likely to be
- Much can be learnt from practices' experience both of proposed change going wrong and of successful change

- Changes resulting from a perceived need internally are more likely to be welcomed than those imposed from outside

- Practice members will have a wide range of different skills to offer and different attitudes towards change

- There must be a workable structure for decision making and style of management

- The way a change is implemented is important to its success

- The effect of change should be evaluated

welcomed and are less traumatic and frustrating than those imposed from outside. This also applies within an organisation; although some members of a practice might feel in control of internally generated change, this does not necessarily apply to others.

\section{What is our attitude to change?}

It is unlikely that all members of the practice feel the same about the benefit or otherwise of change. In any group some will be good at having new ideas, others at analysing positive and negative features of proposals for change, and others at actually initiating change and making it work. As well as there being such a range of skills, attitudes to change will also differ. Some may be naturally conservative and difficult to persuade that any change is better than the status quo. Others may resist change for more pragmatic reasons and argue that it is not worth the disruption it would cause. At the other end of the spectrum some may enjoy the process of change and respond to problems by suggesting a change to the system rather than by trying to make existing arrangements work.

Such a mixture is beneficial to an organisation-if everyone excelled at new ideas but not at following them through little change would occur and all would be frustrated. The benefit of such a mix of skills and attitudes, however, can be realised only if individuals are aware of their own attributes and those of others. Practices may wish to explore this in a formal way by using recognised psychological tests or informally 


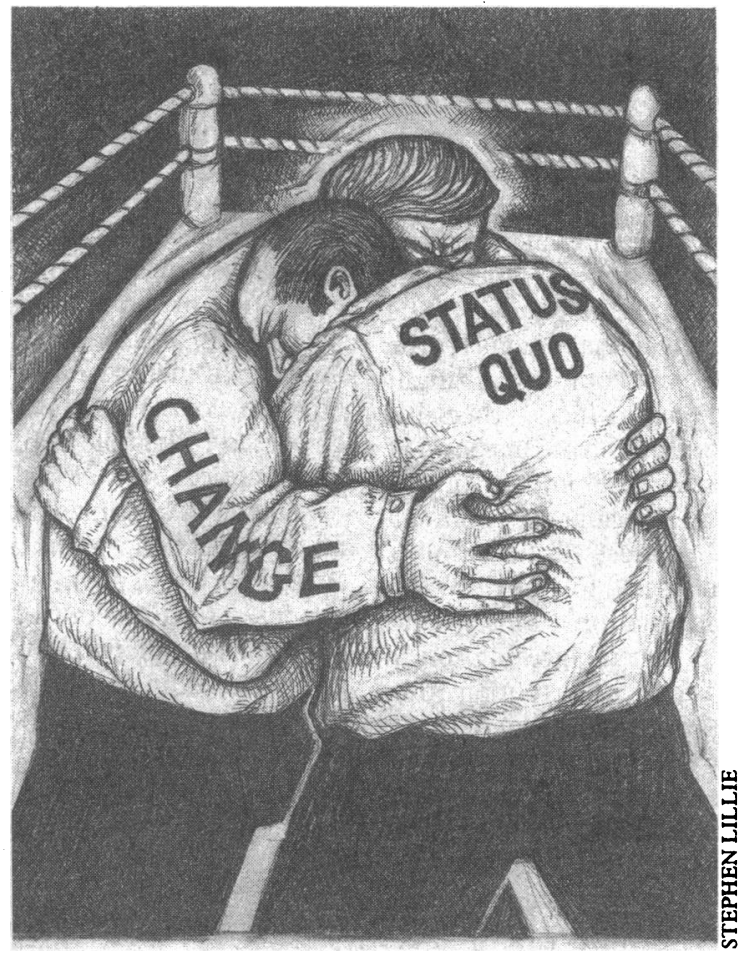

through discussion. As well as differences in attitude, the reaction to change at both individual and practice level will be determined by previous events and current morale. An unsuccessful attempt at change or low morale might leave members feeling bruised and defensive.

\section{How are changes initiated?}

However good the mix of talents, change can be successful only if a suitable structure for decision making and management exists. If the past has been too turbulent a practice might conclude that this is because change is initiated too readily, without proper consultation. Alternatively, a practice might decide that too much consultation and attempt to consensus have occurred, resulting in any innovation being squashed. Each practice needs to establish its own style of management and to find a method that suits participants. However, the style has to be agreed; problems will arise if some members think the chosen style is democratic and consultative, while others are working to a more hierarchical system.

As well as style of management, practices should consider whether decisions about change are made at the appropriate level of organisation. Should a practice manager have the sole responsibility to select reception staff? Should a partner's proposal to change the hours of a surgery be discussed with receptionists only after a decision has been reached? Problems may arise if decisions are made at an inappropriate level, or more commonly because no policy has been established on the mechanism to be used.

\section{How has change been implemented?}

The implementation of change raises similar issues. Some members of the practice are likely to be better than others at implementing an agreed proposal. The way a change is implemented is a major determinant of its success. How are those not involved in the initial decision informed of the proposal? How much modification is acceptable? How are the fears of those against the proposal dealt with? Changes implemented gradually are less likely to be disruptive but more likely to be frustrating to those in support. Should there be a pilot or trial period? Some new initiatives are bound to fail. What safeguards have been constructed so that if this should happen chaos does not result? It may be worth demonstrating the feasibility of a new system before irrevocably abandoning the old.

\section{How has change been evaluated?}

The most neglected aspect of change, particularly by those who enjoy the process, is the assessment of whether the change has been successful. If changes found to be counterproductive are not withdrawn the organisation will rightly become resistant to future initiatives. Evaluation is possible only if there has been a clear statement of the purpose and content of a proposed change. The ultimate objective of a change may be immeasurable - for example, a practice would not be able to show the effect of its new diabetic clinic on mortality and morbidity. However, process and intermediate outcomes are measurable-for example, it would be possible to audit who was invited to the clinic, who attended, and whether designated procedures were followed during the attendance. It is important to consider unpredicted effects of change, and those produced elsewhere in the organisation - the new diabetic clinic may have been very successful in achieving its objectives, but due to overrunning led to unacceptable waiting times in the surgery session which followed it.

\section{What experiences of change can we learn from?}

The scenario at the beginning of this article is an example of how a proposed change failed. Failure may also arise at a later stage. As well as reviewing change in general, as suggested above, specific attempts at change, successful or unsuccessful, may give further insights into how the practice can work best.

The first consideration is the background to the change-what was the morale of the practice and individuals? Were individuals defensive or confident? Who introduced the proposal, and why, and with what prior consultation? How was the idea introduced, how was it negotiated, and who was consulted? How was a decision about the proposal made and was it unanimous? How was the change implemented and evaluated?

\section{EXAMPLES}

Below we describe how this process might work, starting with the scenario at the beginning of this article. We can perhaps see why this proposal went wrong. Examining the process in detail, in the light of the factors mentioned above, may provide further insights that could help this practice in the future.

\section{Past experience}

Looking back to the recent past would show that change in the working arrangements in this practice had always proved difficult. Many other proposed changes had been blocked by the senior partner, whose attitude to change had always seemed to favour the status quo. The partners, who were being expected to cover the extra nights on call, had not perceived a need for this change and therefore were unlikely to be keen on it, particularly in the light of their previous experiences. The overall impact of the proposal, the advantages and the drawbacks, had not been considered or discussed, and none of the parties had looked at the issues from their colleagues' point of view. In an attempt to rush things through, the normal decision making rules had been bypassed and actual implementation of the change proposed with immediate and apparently permanent effect. 


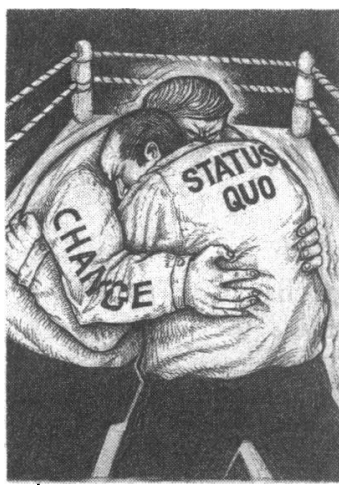

\section{Introduction of the idea}

What might have happened if the factors outlined previously had been taken into account by the partnership concerned? It is, of course, not possible for them to change their recent past. The abruptness of the proposal, however, might have been better handled if the senior partner had introduced the idea at a previous meeting, suggesting its discussion next time. This would allow them all time to get used to the idea of the change. If, in addition, he had given the reasons for the request - he was having problems coping with night calls, particularly since a recent illness - then his partners could start to consider things from his point of view. At the definitive meeting the impact of the proposal could then have been evaluated from all points of view. If any of the parties still had doubts a trial period could be proposed, followed by an evaluation and possible renegotiation. This would allow them all to be reassured that in agreeing to the change they would not prejudice their current position too much. In the event, the partners concerned finally agreed to a plan very similar to this, but only after a further meeting to resolve all the ill feeling previously generated. This partnership decided that in future, when making a major change, they should look at their previous experiences and by planning things better they would not make the same mistakes again.

\section{Improved methods}

Moving along a few years we can see the same partnership approaching another major change differently. On this occasion the proposal was to reduce the number of partners in order to improve earning potential. This was made possible by the withdrawal of an existing partner. Early in the deliberations one of the remaining partners suggested that the partnership should consider the advantages of not appointing a replacement. The practice had adopted some quite radical changes in the previous year or so and had coped with them without difficulty. A clear evaluation of the pros and cons was prepared for the partnership meeting, with an analysis of the likely increase in income and a management plan indicating how the extra work was to be dealt with, and this was discussed fully. The impact on individual members of the practice, as well as the whole group, was also considered. An immediate decision was not demanded, and the decision was taken over two or three meetings. A trial period of six months with a full evaluation was proposed from the outset, and the upshot was that the change was implemented without a hitch. Interestingly, the partnership concerned, on reviewing that decision at the end of the trial period, changed its mind and agreed the need for a replacement partner, again without a problem.

\section{Conclusion}

In all organisations change is occurring all the time. It may go smoothly, but it may cause problems. If it goes badly wrong it can cause a great deal of stress, often needlessly. By looking back at the way changes have occurred in the past it is possible to identify where things have gone wrong. If lessons can be learnt and then applied the process will be much smoother.

\section{A PAPER THAT CHANGED MY PRACTICE}

\section{Loss of naivety or innocence}

I lost my innocence, or some of the vestiges thereof, as I read Roy Meadow's article on Munchausen syndrome by proxy in 1982. It described how an apparently norma parent would fabricate illness in her or, rarely, his child and how that parent would sit back and watch as the medical profession abused the child with countless invasive tests, performed in good faith. Two of Roy Meadow's original 19 children had already died. Like many another doctor I had a sinking feeling as I tried to think of those children I had seen with bizarre and unexplained symptoms.

One of them was 9 months old when I first saw her. Her parents had had a baby who died at birth and still visited the grave every day. The little girl was reported to have had fits since the age of 3 months, but whenever we saw her she looked in the pink of health. Her mother gave a graphic description of her grand mal convulsions, but then the mother's handicapped sister had convulsions as a child. The electroencephalogram was normal but, convinced by the history, we had started her on phenobarbitone. As I read Roy Meadow's paper I realised that we had never witnessed a convulsion. I wrote to my consultant at the time expressing my concerns. He wrote back to say that the child had been admitted extremely drowsy and was found to have a high serum pheno- barbitone concentration. A case conference had been held and the girl's mother had burst in screaming that they could not take her baby away from her.

Since then I have seen children failing to thrive because of a parentally imposed restrictive diet for imagined food allergy. I have seen children with recurrent septicaemias with multiple organisms caused by a mother injecting faeces into the child's vein. I have heard of a girl with recurrent glycosuria despite normoglycaemia, who had been coached by her mother to squeeze a concentrated glucose solution from one eye of her doll into urine specimen pots.

Now, whenever I hear of a child with unusual symptoms I consider the possibility of Munchausen syndrome by proxy. Probably this is good medicine. Perhaps it was my naivety that I lost rather than my innocence in 1982 . But each time I contemplate the diagnosis of Meadow's syndrome, as it is now often called, it is with immense sadness at the child's suffering and the suffering of parents who could be so disturbed as to harm their own child by proxy in such a bizarre ritual.-DAVID ISAACS, head, department of immunology and infectious diseases, Royal Alexandra Hospital for Children, Sydney, Australia

Meadow R. Munchausen syndrome by proxy. Arch Dis Child 1982;57:92-8. 